\title{
Trypanosoma cruzi reservoir - triatomine vector co-occurrence networks reveal meta-community effects by synanthropic mammals on geographic dispersal
}

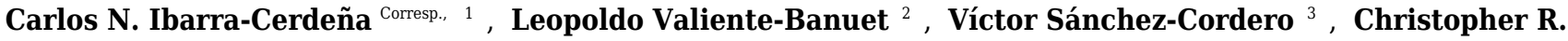 \\ Stephens ${ }^{4,5}$, Janine M. Ramsey ${ }^{\text {Corresp. } 6}$ \\ 1 Departamento de Ecología Humana, Centro de Investigaciones y Estudios Avanzados (Cinvestav) del IPN Unidad Merida, Mérida, Yucatán, México \\ 2 Centro de Ciencias de la Complejidad (C3), Universidad Nacional Autónoma de México, Ciudad de México, México \\ 3 Instituto de Biología, Universidad Nacional Autónoma de México, Ciudad de México, México \\ 4 Instituto de Ciencias Nucleares, Universidad Nacional Autónoma de México, Ciudad de México, Mexico \\ 5 Centro de Ciencias de la Complejidad, Universidad Nacional Autónoma de México, Ciudad de México, Mexico \\ ${ }^{6}$ Centro Regional de Investigaciones en Salud Pública, Instituto Nacional de Salud Pública, Tapachula, Chiapas, México \\ Corresponding Authors: Carlos N. Ibarra-Cerdeña, Janine M. Ramsey \\ Email address: ibarra.cerdena@gmail.com, jramsey@insp.mx
}

Contemporary patterns of land use and global climate change are modifying regional pools of parasite host species. The impact of host community changes on human disease risk, however, is difficult to assess due to a lack of information about zoonotic parasite host assemblages. We have used a recently developed method to infer parasite-host interactions for Chagas Disease (CD) from vector-host co-occurrence networks. Vector-host networks were constructed to analyze topological characteristics of the network and ecological traits of species' nodes, which could provide information regarding parasite regional dispersal in Mexico. Twenty-eight triatomine species (vectors) and 396 mammal species (potential hosts) were included using a data-mining approach to develop models to infer most-likely interactions. The final network contained 1576 links which were analyzed to calculate centrality, connectivity, and modularity. The model predicted links of independently registered Trypanosoma cruzi hosts, which correlated with the degree of parasite-vector co-occurrence. Wiring patterns differed according to node location, while edge density was greater in Neotropical as compared to Nearctic regions. Vectors with greatest public health importance (i.e. Triatoma dimidiata, T. barberi, T. pallidipennis, $T$. longipennis, etc), did not have stronger links with particular host species, although they had a greater frequency of significant links. In contrast, hosts classified as important based on network properties were synanthropic mammals. The latter were the most common parasite hosts and are likely bridge species between these communities, thereby integrating meta-community scenarios beneficial for long-range parasite dispersal. This was particularly true for rodents, $>50 \%$ of species are synanthropic and more than $20 \%$ 
have been identified as $T$. cruzi hosts. In addition to predicting potential host species using the co-occurrence networks, they reveal regions with greater expected parasite mobility. The Neotropical region, which includes the Mexican south and southeast, and the Transvolcanic belt, had greatest potential active $T$. cruzi dispersal, as well as greatest edge density. This information could be directly applied for stratification of transmission risk and to design and analyze human-infected vector contact intervention efficacy. 
1

2

3

4

5

6

7

8

9

10

11

12

13

14

15

16

17

18

19

20

21

22 Abstract

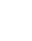

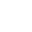

5

7

8

9

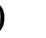

1

2

3

4

5

6

17

Trypanosoma cruzi reservoir - triatomine vector co-occurrence networks reveal metacommunity effects by synanthropic mammals on geographic dispersal

Ibarra-Cerdeña $\mathrm{CN}^{1 *}$, Valiente-Banuet $\mathrm{L}^{2}$, Sánchez-Cordero $\mathrm{V}^{3}$, Stephens $\mathrm{CR}^{2,4}$ and JM

$$
\text { Ramsey } 5 *
$$

${ }^{1}$ Departamento de Ecología Humana, CINVESTAV del IPN Unidad Mérida

${ }^{2}$ Centro de Ciencias de la Complejidad, UNAM, México DF ${ }^{3}$ Instituto de Biología, UNAM, México DF ${ }^{4}$ Instituto de Ciencias Nucleares, UNAM, México DF ${ }^{5}$ Instituto Nacional de Salud Pública, Mexico *corresponding authors: cibarra@cinvestav.mx,jramsey@insp.mx 
23 Contemporary patterns of land use and global climate change are modifying regional pools of

24 parasite host species. The impact of host community changes on human disease risk, however, is 25 difficult to assess due to a lack of information about zoonotic parasite host assemblages. We

26 have used a recently developed method to infer parasite-host interactions for Chagas Disease

27 (CD) from vector-host co-occurrence networks. Vector-host networks were constructed to

28 analyze topological characteristics of the network and ecological traits of species' nodes, which

29 could provide information regarding parasite regional dispersal in Mexico. Twenty-eight

30 triatomine species (vectors) and 396 mammal species (potential hosts) were included using a

31 data-mining approach to develop models to infer most-likely interactions. The final network

32 contained 1576 links which were analyzed to calculate centrality, connectivity, and modularity.

33 The model predicted links of independently registered Trypanosoma cruzi hosts, which

34 correlated with the degree of parasite-vector co-occurrence. Wiring patterns differed according to

35 node location, while edge density was greater in Neotropical as compared to Nearctic regions.

36 Vectors with greatest public health importance (i.e. Triatoma dimidiata, T. barberi, T.

37 pallidipennis, T. longipennis, etc), did not have stronger links with particular host species,

38 although they had a greater frequency of significant links. In contrast, hosts classified as

39 important based on network properties were synanthropic mammals. The latter were the most

40 common parasite hosts and are likely bridge species between these communities, thereby

41 integrating meta-community scenarios beneficial for long-range parasite dispersal. This was

42 particularly true for rodents, $>50 \%$ of species are synanthropic and more than $20 \%$ have been

43 identified as T. cruzi hosts. In addition to predicting potential host species using the co-

44 occurrence networks, they reveal regions with greater expected parasite mobility. The

45 Neotropical region, which includes the Mexican south and southeast, and the Transvolcanic belt, 
46 had greatest potential active T. cruzi dispersal, as well as greatest edge density. This information

47 could be directly applied for stratification of transmission risk and to design and analyze human-

48 infected vector contact intervention efficacy.

Introduction

51 Many of the most important and yet neglected human infectious diseases, such as Chagas

52 Disease (CD), Leishmaniasis, Onchocerciasis, and Schistosomiasis, (Lozano et al. 2012; Murray

53 et al. 2012), have etiologic agents that are transmitted among multiple vector and reservoir

54 species (Taylor et al. 2001; Heesterbeek et al. 2015). Among these, the protozoan parasite

55 Trypanosoma cruzi is responsible for human trypanosomiasis and Chagas Disease (CD). A

56 century after its discovery (Chagas 1909), CD continues to be among the main neglected tropical

57 diseases in Latin America, based on mortality, disability-adjusted life years lost (DALYs), and at

58 risk population (Hotez et al. 2008). This chronic parasitic disease is the most frequent cause of

59 heart failure in rural populations of endemic countries (Rassi et al. 2010; Bui et al. 2011), where

60 primary parasite transmission occurs due to human contact with $T$. cruzi contaminated bug faeces,

61 during the vector's bloodmeal.

62

63 The Kinetplastid, Trypanosoma cruzi (Trypanosomatidae) is an obligate parasite that alternates

64 between invertebrates (kissing bugs belonging to the family Reduviidae) and terrestrial

65 mammals. It has low species-host specificity along its geographic range in the American

66 continent (Izeta-Alberdi et al. 2016), which may be explained by intrinsic factors related to

67 sophisticated host defense response mechanisms (Freire-de-Lima et al. 2012; Caballero et al.

68 2015) and to extrinsic factors that ensure persistence and transmission in vector-host 
69 communities. These latter factors may be associated with vectors and mammal host contact rates

70 which in turn depend on habitat disturbance (Ramsey et al. 2012; Lopez-Cancino et al. 2015;

71 Gurtler \& Cardinal 2015). These host-compatibility and host-encounter filters define the

72 potential spectrum of parasites in hosts (Krasnov et al. 2008). Whereas host-compatibility, with

73 early evolution of the mechanism for T. cruzi host cell invasion (Caballero et al. 2015; Jackson

74 et al. 2016), has deep phylogenetic roots, host-encounter filters are more labile and depend on

75 community assemblages and host species' population dynamics at local levels (Kribs-Zaleta

76 2010).

Contemporary patterns of land use and global climate change modify regional species

pools in multiple ways: on the one hand species interactions are being lost via local extinctions,

and on the other they are gained via invasions which have as yet unknown net effects on

ecosystem functioning (Dirzo et al. 2014). The modification of species assemblages resulting

81 from disrupted trophic networks can affect parasite dynamics via cascade effects such as

increasing contact rates between competent reservoirs and vectors (Young et al. 2014). This is important to consider from a public health perspective, since species linked to zoonotic diseases may be positively affected by anthropogenic disturbance, such as habitat fragmentation (Rubio et al. 2014), defaunation (Young et al. 2015), or land-use change (McCauley et al. 2015). An increase in host ranges due to altered suites of niche conditions may trigger new metacommunity arrays (i.e. local communities linked by dispersal of a number of interacting species), thereby benefiting long-range parasite dispersal (Suzán et al. 2015). These changes will

89 inevitably affect the geographic pattern of vector-reservoir interactions and generate the opportunity for parasite flux across landscapes (González-Salazar and Stephens 2012). 
91 Since ecological communities have complex patterns in space and time (Bascompte

92 2010), studying species interactions requires an approach that includes their key properties. A

93 relatively new paradigm to study community complexity comes from network theory (Green and

94 Sadedin 2005; Bascompte 2009), in which communities are depicted as wiring graphs and

95 species are nodes connected by links based on their biotic interactions (Fortuna and Bascompte

96 2008). The network approach focuses on the pattern of node interactions, key components of the

97 network architecture (Bascompte and Stouffer 2009). This approach has enlightened

98 epidemiology by identifying network properties such as node centrality (i.e. relative intensity of

99 connections with other nodes in the network, interpreted as node importance), which is related to

100 node heterogeneity and affects the probability of pathogen spread by a host (Gómez et al. 2013).

101 Network heterogeneities related to modularity (i.e. the extent to which the networks are

102 subdivided in different modules of interacting species) have been used to understand how muti-

103 host systems affect parasite sharing (Pilosof et al. 2015). Network modularity is greater in more

104 complex communities of host-parasite networks, with parasite dynamics related to host

105 phylogeny. Tick-borne pathogens are influenced more by host habitat sharing as compared to

106 their phylogenetic proximity (Estrada-Peña et al. 2015), while host-parasite interactions are more

107 associated to the latter. Hence, naturally disrupted pathogen transmission routes can be

108 "connected" by synanthropic animals (i.e. those species that can exploit human-modified

109 habitats; [McFarlane et al. 2012]). Synanthropy is not necessarily a definitive state, since it may

110 decline when few resources are available in anthropogenic habitats, and hosts may maintain

111 sylvatic populations (Shochat et al. 2006). Irrespective of taxa, synanthropic species are most

112 likely to be disease hosts (McFarlane et al. 2012). 
114 (Craft and Caillaud 2011), while that for less documented or more complex networks may be

115 constructed using species co-occurrence networks (Stephens et al. 2009), which are based on the

116 concept that at coarse-grained scales, interspecific interactions are associated with species co-

117 occurrences (Gotelli 2000). Distributional patterns may reflect evolved ecological relationships

118 that confer either symmetrical or asymmetrical benefits when species occupy the same

119 environment at the same time (Cazelles et al. 2016), thereby affecting community structure and

120 function (DiMichele et al. 2004). This is particularly true for specialist guild groups, such as

121 blood-sucking insect disease vectors, and the parasites they disperse (Lehane 2005). Whereas

122 host community composition over minor spatial (several meters) and temporal (several years)

123 scales typically fluctuates widely in response to local disturbance, observations over hundreds of

124 meters to thousands of kilometers are more predictable and have persistent patterns (Jackson and

125 Erwin 2006). The latter has been reported due to long-term stasis in species occurrences

126 (DiMichele et al. 2004) primarily due to niche constraints (Martínez-Meyer et al. 2004), or to

127 the stability of biotic interactions (Morris et al. 1995).

128 Trypanosoma cruzi vectors are blood-sucking insects of the Triatominae

129 (Reduviidae:Hemiptera) that feed on terrestrial vertebrates and are obligate sanguivores. While

130 triatomines seem to be eclectic in their blood sources, they most frequently feed on terrestrial

131 mammals (Noireau et al. 2009). A possible outcome of the triatomine-mammal interaction is the

132 transmission of T. cruzi, a parasite unique to this class (Kierszenbaum et al. 1981). With the

133 exception of a few reports of triatomine-host interactions in North America that list the mammal

134 species from which bugs feed (Ibarra-Cerdeña et al. 2009), few empirical studies have provided

135 evidence for triatomine host community assemblages (Izeta-Alberdi et al. 2016). The complexity 
136 of vector-reservoir assemblages associated with $T$. cruzi transmission (i.e. number and strength

137 of species interactions) has been associated with a gamut of transmission conditions in natural

138 sylvatic areas (Jansen et al. 2015; Lopez-Cancino et al. 2015; Izeta-Alberdi et al. 2016),

139 anthropogenic ecotones (Ramsey et al. 2012), and urban habitats (Delgado et al. 2011; Ramsey

140 et al. 2005). Host use by triatomines is influenced by the habitat they colonize, and that host

141 accessibility may be a major factor shaping the blood-foraging patterns of these bugs

142 (Rabinovich et al. 2011). At a coarse-grain scale, their more common hosts could be species with

143 the highest exposure probability, where exposure is defined as the level of geographic co-variation

144 between every bug species and every potential host. If co-occurrence patterns between

145 triatomines and mammals are indicative of a potential vector-host interaction, a significant

146 interaction should occur for those species pairs that are confirmed blood sources of

147 triatomines and/or mammal reservoirs of T. cruzi. We used this argument to model biotic

148 interactions between $T$. cruzi vectors (triatomines) and their hosts (mammals). We analyze

149 empirically identified or evidence-based interactions to evaluate a network model's

150 performance and address the following questions: (1) is regional host species richness related

151 to the frequency of vector-host geographic co-distributions? Specifically, what is the most likely

152 host for a particular vector species? A resulting hypothesis for this latter question is that host

153 species richness (i.e. blood source availability) drives the vector's geographic dependence. (2)

154 are vector-host co-distributions related to the transmission of T. cruzi? Specifically, do vector-

155 host co-distributions predict host-T. cruzi interactions? Our hypothesis is that known T. cruzi

156 hosts will have stronger correlations with vector species within their geographic range. (3) is

157 there a relationship between vector-host geographic "interactions" and human exposure to $T$. 
158 cruzi? The hypothesis is that synanthropic hosts and vectors play, within their geographic range,

159 a significant role in complex network topology.

160

161 Materials and Methods

162 Vector and mammal reservoir data

163 Georeferenced data points for triatomines and terrestrial mammal collection sites in Mexico were

164 used to model interactions. For triatomines, we compiled a database consisting of all documented

165 data collections since 1979 (publication of the first global monograph of Triatominae by Lent

166 and Wygodzynsky which re-assigned many autochthonous Mexican species complexes),

167 published in technical reports (Mexican National Health Secretary), scientific publications, or

168 scientific collections (i.e. INSP, INDrE and IBUNAM), that includes 1600 data points for 26

169 Mexican triatomine species (Ramsey et al. 2015; doi: 10.5061/dryad.rq120). Mammal data

170 points were retrieved from the Global Biodiversity Information Facility (GBIF; www.gbif.org),

171 registered for Mexican collections (last accessed in February of 2011). We obtained 36000

172 records for 396 mammal species, which were all used for network construction.

173 Interaction model based on vector-mammal co-distributions

174 The methodology for the vector-host interaction inference we will use is that of (Stephens et

175 al. 2009) which we describe here for completeness. Triatomine species hosts are a subset of all

176 terrestrial mammal species present in their distribution range $I^{\prime} \subseteq I$. Let the difference of the

177 probabilities $\mathrm{P}\left(\mathrm{B}_{\mathrm{i}} \mid \mathbf{I}^{\prime}\right)-\mathrm{P}\left(\mathrm{B}_{\mathrm{i}}\right.$ be the probability of the presence of a particular triatomine

178 species $\left(\mathrm{B}_{\mathrm{i}}\right)$ occurring given the presence of a particular mammal species $\left(\mathbf{I}^{\prime}\right)$. To calculate

179 this probability, we used a grid size $\mathrm{N}$ of $0.25^{\circ}$ for the cell size. The robustness of the results with

180 respect to changes in the grid size were considered in Stephens et al (2009). The grid covers the 
181 area of all ecoregions where the species $\mathrm{Bi}$ has been reported. We consider this probability

182 relative to the null hypothesis that $\mathrm{B}_{\mathrm{i}}$ and $\mathbf{I}^{\prime}$ are uncorrelated and hence $\mathrm{P}\left(\mathrm{B}_{\mathrm{i}} \mid \mathbf{I}^{\prime}\right)=\mathrm{P}\left(\mathrm{B}_{\mathrm{i}}\right)$.

183 Then, $\mathrm{P}\left(\mathrm{B}_{\mathrm{i}} \mid \mathrm{I}^{\prime}\right)-\mathrm{P}\left(\mathrm{B}_{\mathrm{i}}\right)=\left(\mathrm{N}_{\mathrm{Bi} \text { and I }} / \mathrm{N}_{\mathrm{I}}^{\prime}\right)-\left(\mathrm{N}_{\mathrm{Bi}} / \mathrm{N}\right)$, where $\mathrm{N}_{\mathrm{Bi} \text { and I }}$ is the number of spatial

184 cells where there is a co-occurrence of the taxon $\mathrm{B}_{\mathrm{i}}$ and the taxon $\mathbf{I}^{\prime}$ (the potential mammal host),

185 and $\mathrm{N}_{\mathrm{I}}^{\prime}$ is the number of cells where that host take their stated values (a Boolean

186 presence/absence value), within the grid. $\mathrm{P}\left(\mathrm{B}_{\mathrm{i}} \mid \mathbf{I}_{\mathrm{k}}\right)$ is the number of co-occurrences of the taxa

$187 \mathrm{~B}_{\mathrm{i}}$ and $\mathbf{I}_{\mathrm{k}}$, and allows us to define the most important statistical associations between these pairs

188 of species distributions. However, since $\mathrm{P}\left(\mathrm{B}_{\mathrm{i}} \mid \mathbf{I}_{\mathrm{k}}\right)$ is a probability, it does not consider sample

189 size. If $\mathrm{P}\left(\mathrm{B}_{\mathrm{i}} \mid \mathbf{I}_{\mathrm{k}}\right)=1$, this may be the result of a coincidence of $\mathrm{B}_{\mathrm{i}}$ and $\mathbf{I}_{\mathrm{k}}$ in one or 1000 spatial

190 cells, the latter being more significant statistically. To adjust for this difference, the following

191 binomial test for statistical significance is used:

192

$$
\varepsilon\left(B_{i} \mid I_{k}\right)=\frac{N_{I_{j}}\left(P\left(B_{i} \mid I_{k}\right)-P\left(B_{i}\right)\right)}{\left(N_{I_{j}} P\left(B_{i}\right)\left(1-P\left(B_{i}\right)\right)\right)^{1 / 2}}
$$

193 Equation (1) measures the statistical dependence of $B_{i}$ on $\mathbf{I}_{k}$ relative to the null hypothesis that

194 the distribution of $\mathrm{B}_{\mathrm{i}}$ is independent of $\mathbf{I}_{\mathrm{k}}$ and randomly distributed over the grid. The

195 sampling distribution of the null hypothesis is binomial, where every cell is given a probability

$196 \mathrm{P}\left(\mathrm{B}_{\mathrm{i}}\right)$ of having a point collection of $\mathrm{B}_{\mathrm{i}}$. The numerator of equation (1), is the difference between

197 the observed number of co-occurrences of $B_{i}$ and $I_{k}$, and the expected number in the case where

198 the distribution of point collections was obtained from a binomial with sampling probability

$199 \mathrm{P}\left(\mathrm{B}_{\mathrm{i}}\right)$. Since this is a stochastic sampling, the numerator must be measured in appropriate "units".

200 As the underlying null hypothesis is that of a binomial distribution, it is natural to measure the

201 numerator in standard deviations of this distribution, which is used as the denominator of

202 equation (1). If $N_{B_{j}} \geq 5-10$, and $\mathrm{P}\left(\mathrm{B}_{\mathrm{i}}\right)$ and $\mathrm{P}\left(\mathrm{B}_{\mathrm{i}} \mid \mathbf{I}_{\mathrm{k}}\right)$ are not too close to zero or one, then a 
203 normal approximation for the binomial distribution is adequate, in which case $\varepsilon\left(\mathrm{B}_{\mathrm{i}} \mid \mathrm{I}_{\mathrm{k}}\right)=1.96$

204 represents the standard $95 \%$ confidence interval. Naturally, as $\varepsilon$ values increase, the hypothesis

205 of interaction becomes stronger. Note that such a statistical association does not necessarily

206 prove that there is a direct "causal" interaction between the two taxa, rather it allows for a

207 statistical inference that should be validated experimentally subsequently or assessed with

208 independent studies from the literature.

209 If co-occurrence patterns between triatomines and mammals are indicative of a vector-host

210 interaction, more significant $\varepsilon$ values should be found for those species' pairs that are

211 confirmed blood sources of triatomines and/or mammal reservoirs of T. cruzi. As a model

212 performance measure, we examine the $\varepsilon$ value for known interactions identified empirically

213 and for those reported in the literature (see Supplemental Table S1). Usually, these reports

214 target specific triatomine species (i.e. the blood source of Triatoma pallidipennis as reported

215 in Mota et al., [2007], etc), therefore, model performance was evaluated using those species

216 for which evidence is available. If the vector-host interaction is an important component of $T$.

217 cruzi transmission, the $\varepsilon$ value should correlate with the probability for a mammal species to be

218 a T. cruzi reservoir. To evaluate this, we listed all confirmed reservoir mammals and conducted

219 the same analysis as described above.

220

221

Description of regional availability of vector hosts and interaction patterns

Vector host availability was measured as the number of mammal species in the vector's

223 distribution range (the grid). This number determines the potential for vector-host interactions

224 and the opportunity for vector specialization. A simple statistical description of frequency

225 distribution of host availability was conducted across vector species to analyze how vectors 
226 relate to mammal species richness. The same procedure was conducted to analyze the number of

227 mammal species with which each vector had an epsilon value $\geq 1.96$. We extracted the mean

228 and standard error from the group of mammals with which each vector had significant

229 interactions to describe comparatively the strength of vector-mammal interactions.

230

231 Validation of the interaction model

232 A literature search was conducted in Google Scholar for publications that report the presence of

233 T. cruzi in Mexican wild mammals and in vector hosts using bloodmeal analysis. We used these

234 records to evaluate the model performance by comparing the distribution frequency of

235 historically confirmed mammal hosts grouped by epsilon range against the distribution frequency

236 of all mammals with no reports of T. cruzi presence. This allowed us to describe the model's

237 predictability across different epsilon values.

238

239 Network construction

240 We used 26 Triatominae species and 396 mammal species (Supplemental table S1) for network

241 vertices (nodes). Vertices were inter-connected representing significant triatomine-mammal

242 geographic associations $(\varepsilon \geq 1.96)$. All species were classified using binary variables associated

243 with their ecological tolerance for anthropogenic habitats (synanthropic vs. non-synanthropic)

244 and with T. cruzi infection, the latter used for model validation (Supplemental table S1). To

245 examine the geographic pattern of vector-mammal potential interactions, a network was

246 projected onto a map of Mexico in which nodes were located according to their range centroid,

247 which was determined as the geographic centroid calculated from the point collections of the

248 node species. We used an automatic procedure to draw the network with a force-directed 
249 algorithm that assigns forces among the set of edges and nodes. Briefly, this algorithm emulates

250 a system as if the edges were springs and the nodes were electrically charged particles. Forces

251 are applied to the nodes, thereby pulling them closer together or pushing them further apart. This

252 is repeated iteratively until the system comes to an equilibrium state $i . e$., their relative positions

253 do not change from one iteration to the next, and the graph is then drawn. The equilibrium state

254 represents all forces in mechanical equilibrium. In the final graph, the position of every node

255 corresponds to their connectivity level, indicating that the most connected vertices are located in

256 the center of the graph and vertices with fewer edges are in the periphery (Kamada and Kawai

257 1989). In order to analyze geographic patterns of vector-mammal interactions relevant for

258 Chagas disease risk, we used modular algorithms to identify network "community structure",

259 which use centrality indices to identify community boundaries. Instead of constructing a measure

260 for edges that are central to communities (as in hierarchical clustering), focus was placed on the

261 least centralized edges that are "between" communities (Newman 2006). Rather than

262 constructing communities by adding the strongest edges to an empty vertex set, they were

263 constructed by progressively removing edges from the original graph. Vertex betweenness was

264 used as the centrality measure, since it reflects the node influence in the network. The

265 betweenness centrality of a vertex $i$ is defined as the number of shortest paths between pairs of

266 other vertices that run through $i$. To find which edges in a network are between other pairs, we

267 generalize betweenness centrality to edges and define the edge betweenness as the number of

268 shortest paths between pairs of vertices. If there is more than one shortest path between a pair of

269 vertices, each path is given equal weight so that the total weight of all of the paths is unity. If a

270 network contains communities or groups that are only loosely connected by a few inter-group

271 edges, then all shortest paths between different communities must attach to one of these edges. 
272 Thus, the edges connecting communities will have high edge betweenness. By removing these

273 edges, we separate groups and reveal the underlying community structure of the graph (Girvan

274 and Newman 2002). We further analyzed the structure of the network by disentangling the

275 relative effect of triatomines and mammals grouped according to their disturbance tolerance

276 (synanthropic and non-synanthropic) and parasite association (T. cruzi and non-T. cruzi), in the

277 network structure. To do this, we analyzed the mean degree of species belonging to each group.

278 The degree of a node is the number of connections (edges) it has to other nodes in the network.

279 Finally, we estimated the vector species' similarity in terms of their mammal host communities

280 using a hierarchical cluster analysis based on the 1- Jaccard similarity coefficient (Legendre et al.

281 2005). All analyses were conducted using the igraph package ver 1.0 for the statistical package R

282 ver 2.15 (http://www.r-project.org). All routines were included in a script written to perform

283 analyses (Supplemental code S3)

284

285 Results

286 The matrix of 28 triatomine and 396 mammal species co-occurrence has 1576 significant links

287 from a total $2695(45 \%)$ possible links after taking into account that we only consider mammals

288 present in the same projected ecoregions as a given vector (Supplemental Table S2).

289 Regional availability of vector hosts and interaction patterns

290 As would be expected, mammal species' number per vector was moderately correlated with

291 vector grid size, i.e., the number of spatial grid cells occupied by a given vector (Spearman rank

292 correlation coefficient $r=0.61, \mathrm{P}=0.001)$. The number of mammals to which vectors had

293 significant epsilon values was less correlated with vector grid size $(r=0.5, \mathrm{P}=0.01)$. Six species

294 of the phyllosoma complex (Triatoma pallidipennis, Triatoma longipennis, Triatoma mazzottii, 
295 Triatoma picturata, Triatoma mexicana, and Triatoma gerstaeckeri), one of the protracta

296 (Triatoma barberi), and two of the dimidiata complex (Triatoma dimidiata hg2, and T. dimidiata

297 hg3), had their distributional ranges which coincided significantly with regions having a high

298 number of mammal species (i.e. higher than the 95\% confidence interval [79-128]). In contrast,

299 eleven triatomine species (Triatoma protracta, Triatoma peninsularis, Triatoma sinaloensis,

300 Triatoma neotomae, Triatoma lecticularia, Triatoma nahuatlae, Triatoma uhleri, Triatoma

301 zacatecensis, Triatoma woodi, Dipetatolagster maximus and Paratriatoma hirsuta) had

302 distribution ranges in regions with a significantly lower number of mammal species (i.e. lower

303 than the $95 \% \mathrm{CI})$. These latter species, conversely, had a higher proportion of significant links (>

$30495 \% \mathrm{CI}$ ) with mammal species with highest mean epsilon values (Figure 1A, Figure 1B). This

305 pattern was inverted in vectors with high availability of mammals, since they had a lower

306 proportion of accessible mammal hosts with significant links (Figure 1B).

307 Rodentia and Chiroptera were the mammal orders with greatest number of species, however

308 orders with the highest proportion of synanthropic species were Didelphimorphia and Rodentia,

309 followed by Carnivora (Table 1). Didelphimorphia had the highest proportion of registered $T$.

310 cruzi infected species, followed by Carnivora. Although Primates, followed by Rodentia, had

311 greatest link strength (mean epsilon), rodents, opossums (Didelphimorphia), and bats

312 (Chiroptera) had highest epsilon values. Opossums and Lagomorphs had the greatest number of

313 links with vector species, although no Lagomorphs have been reported infected with the parasite.

315 Vector-host co-occurrence and Trypanosoma cruzi transmission

316 All mammal species known to be T. cruzi hosts had significant epsilon values with at least one

317 vector. The distribution frequency of host mammals was skewed positively with the magnitude 
318 of epsilon, in contrast to those mammals which have not been reported infected with $T$. cruzi.

319 There was a significant difference between the proportion of T. cruzi hosts with high epsilon

320 values, and the proportion of non-hosts with high epsilon (Figure 2).

321 Network topology and the importance of synanthropic hosts

322 The interactions wiring patterns differed depending on the spatial position of the

323 geographic centroid of vector and host ranges (Figure 3). Edge density is higher in the

324 Neotropical region, in central and southeast Mexico, as compared to the Nearctic region in the

325 north. Synanthropic species (both triatomine and mammal) shape the Kamada-Kawai force-

326 directed network structure, as indicated by their position in the center of graphs, while most non-

327 synanthropic species are located on the periphery (Figure 4). The structure of the complete array

328 of mammals and vectors that can be considered relevant for the T. cruzi dispersal provided their

329 geographic associations were not random, includes all significant links $(\varepsilon>1.96)$ (Figure 4).

330 Mammals which are both synanthropic and T. cruzi-infected are the most central in the network.

331 These synanthropic mammals remained in greater proportion (compared to non-synanthropic

332 mammals) in networks with higher epsilon values $(\mathcal{E}>>2)$. In general, this last group of

333 mammals (synanthropic and reported reservoirs), had proportionally more significant links than

334 the group of registered reservoir species that are non synanthropic $(\mathrm{OR}=1.17,95 \% \mathrm{CI}=1.01$ -

335 1.4). At highest epsilon values $(\varepsilon \geq 8)$, the network connectivity was reduced due as showed by

336 the presence ofisolated clusters (Figure 4), although these clusters had several nodes of

337 synanthropic/T. cruzi reservoir species. For instance, Triatoma dimidiata hg1 (node 365) had 21

338 links in the network with $\varepsilon \geq 10$, and $9(43 \%)$ of those links were synanthropic and $T$. cruzi

339 reservoirs. 
Network connectivity, as measured by node degree, decreased exponentially with an

341 epsilon increase, both in vectors (Figure 5A) and mammals (Figure 5B). Synanthropic vectors

342 were more connected than non-synanthropic ones (Figure 5A). Similarly, synanthropic reservoirs

343 of $T$. cruzi were more connected than other groups, particularly at low yet significant epsilon

344 values (Figure 5B). All groups had the same pattern of connectivity decrease with increasing

345 epsilon, except for non-synanthropic reservoirs.

346 Two principal clusters emerged from the complete geographic model network. These

347 clusters differed according to number of species and geographic region. The first cluster was

348 composed principally of phyllosoma (7 species) and dimidiata (two haplogroups) complex

349 species and 171 mammals, while the second cluster contained principally protracta and rubida

350 complexes (17 vector species and subspecies) and had 183 mammals. The more dominant

351 species of this latter group are T. rubida, T. uhleri and T. woodii. Several mammal and vector

352 species were intermediate between these two former groups and could not be assigned to either:

353 T. dimidiata hg1, T. barberi, T. longipennis, T. mexicana, and T. pallidipennis (Figure 6).

354 Hierarchical similarity of vectors constructed from mammal hosts produced two main clusters.

355 Most synanthropic vectors were grouped into one cluster, while most non-synanthropic species

356 were separated into a second cluster (Figure 7).

358 Discussion

A spatial data-mining modeling approach, based on Complex Inference Networks

360 (Stephens et al. 2009), has been used herein to predict vector-host interactions that could be

361 meaningful for T. cruzi vector transmission and Chagas disease risk. Our results confirm that this

362 approach can lead to accurate predictions of yet unidentified or unconfirmed species' interactions 
363 using public domain curated data, as has been demonstrated for predicting unknown hosts of

364 Leishmania mexicana (Stephens et al. 2009, Stephens et al. 2016). This highlights the value of

365 natural history museum and scientific collections to analyze ecological processes that affect

366 human populations (Sánchez-Cordero and Martínez-Meyer 2000). Our interaction model

367 correctly predicted known mammal-parasite interactions using only geographic associations

368 between infected vector and mammal reservoir species. Moreover, T. cruzi reservoirs most

369 frequently occur within the highest rank of epsilon values. Since epsilon measures the statistical

370 geographic association of vectors and mammals, the model additionally predicts interaction

371 patterns which may influence parasite transmission and highlights how local interactions are

372 affected by large-scale processes, previously demonstrated using spatial scaling models (Brose et

373 al. 2004).

374 The geographic ecology of vector-host interactions in North American triatomines was

375 first studied by (Peterson et al. 2002). These authors focused on the protracta complex, which

376 had been reported to specialize on woodrats as a natural blood source (Ryckman 1986). Using

377 climatic niche modeling for hosts and vectors, associations for as yet unidentified hosts of

378 Triatoma barberi, one of the primary T. cruzi vectors in Mexico, were predicted (Peterson et al.

379 2002). The present study extends the former to all Mexican vectors and to all potential terrestrial

380 mammal T. cruzi reservoirs, by directly evaluating their potential biotic interactions. Protracta

381 complex species occurring in both Nearctic and Neotropical regions, had significant epsilon

382 values, with a high proportion of mammals inhabiting their distributional range sharing

383 interactions with several species. This large-scale ecological similarity could be causing a shift in

384 host selection among protracta species, as confirmed by collection efforts (Ramsey, personal

385 communication), an hypothesis addressed in lizard communities (Losos et al. 2003). In contrast, 
386 strictly Neotropical vector species, which are more permissive in host selection, have epsilon

387 patterns consistent with low reliability on single hosts, and are associated with synanthropic

388 mammals (Rabinovich et al. 2011; Ramsey et al. 2012).

389 Vectors occurring in intermediate network nodes (T. dimidiata hg1, T. barberi, $T$.

390 longipennis, T. mexicana, and T. pallidipennis), between the two major communities, are

391 responsible for more than $50 \%$ of $T$. cruzi transmission in Mexico (Ramsey et al. 2015). Hence,

392 these species are important in generating a meta-community scenario within the network, and in

393 maintaining parasite connectivity between the two other vector groups. Synanthropic mammals

394 are keystone components of the geographic structure of triatomine-mammal network interactions.

395 Although synanthropy is a relatively recent phenomenon, it signifies that fauna derive survival

396 advantage from co-existence in human or human-related environments (McFarlane et al. 2012).

397 It is clear that the continuous provision of resources for mammal reservoirs, due to agriculture,

398 food storage, garbage, livestock, land-use changes, and refuge, and hence triatomine blood

399 resources year round, provide this fitness advantage (McKinney 2002; DeStefano and DeGraaf

400 2003; Francis and Chadwick 2012). Expanding synanthropic populations are associated,

401 therefore, with the degree of human landscape transformation (Khlyap and Warshavsky 2010).

402 The importance of synanthropic mammals as meta-community agents within landscapes in

403 Mexico has been previously proposed (Ramsey et al. 2012; Lopez-Cancino et al. 2015). These

404 authors suggested that disturbance-tolerant species, such as some rodent species, opossums, and

405 bats, can connect host communities linked to specific habitats (i.e. conserved forests, cleared

406 crop areas, or urban habitats). This provides an opportunity for T. cruzi flux within the landscape

407 matrix over short periods, such as between seasons. Altered proportional occupancy by parasite

408 reservoirs due to habitat fragmentation, however, can provoke the loss of network connectivity 
409 (Bordes et al. 2015). If remaining species are highly mobile and tolerant to habitat disturbance,

410 spatial connectivity of ecological interactions will increase. On a broader scale, major

411 biogeographic regions in Mexico (Nearctic and Neotropical) can be connected by synanthropic

412 species that persist after chronic disturbance, such as after land-cover changes for urbanization or

413 agriculture. Although, the importance of such a mechanism over greater distance or longer

414 periods has yet to be assessed, present results indicate that there is a biogeographic region

415 association with triatomine-mammal interactions that depends on the specific community

416 structure, connected by synanthropic species (Izeta-Alberdi et al. 2016).

417 Some species' groups associated with anthropozoonotic diseases have adapted to be

418 almost completely synanthropic, such as dengue (Lambrechts et al. 2010), or partially

419 synanthropic, such as American trypanosomiasis (Gaunt and Miles 2000). A gradient of

420 synanthropy occurs in T. cruzi vector species in North America (Ibarra-Cerdeña et al. 2009),

421 with highly synanthropic species, such as T. pallidipennis and most phyllosoma complex species

422 (Enger et al. 2004; Cohen et al. 2006; Ramsey et al. 2012) and T. dimidiata haplogroups

423 (Dumonteil and Gourbiére 2004; Guzmán-Tapia et al. 2007, Lopez-Cancino et al. 2015), or

424 partially synanthropic, such as T. barberi (Ramsey et al. 2000; Martínez-Ibarra 2008). Reservoirs

425 such as Rattus rattus or Mus musculus represent the case for highly synanthropic rodent species

426 (Khlyap and Warshavsky 2010), and Sigmodon hispidus or Liomys irroratus as partially

427 synanthropic, all of them important reservoirs of T. cruzi (Ramsey et al. 2012, Lopez-Cancino et

428 al. 2015). The present results are highly relevant for sustainable and cost-effective control of

429 domestic or agricultural-related triatomine colonization, based on species' interaction scenarios

430 with synanthropic reservoirs (Peterson et al. 2002; Maher et al. 2010). Evolutionary studies of $T$.

431 cruzi diversification patterns indicate that long-term interaction with particular host species, , 
432 may have had an influence on their phylogeny (Yeo et al. 2005). Most recent studies highlight

433 the potential biogeographic impact of bats, their ability to disperse parasites over a greater range,

434 and on their role in phylogenetic diversification of the T. cruzi clade (Hamilton et al. 2012, Lima

435 et al. 2015, 2016). We hypothesize that the large-scale network topology is critical for the

436 geographic dispersal and diversification of $T$. cruzi, mediated principally by large-scale

437 landscape transformation, and encourage research which traces $T$. cruzi population genetics and 438 phylogeographic patterns using ecological network models as a template.

439

440 References

441 Bascompte, J. 2009. Disentangling the web of life. Science 325:416-9.

442

443 Bascompte, J. 2010. Ecology. Structure and dynamics of ecological networks. Science 329:7654446.

445

446 Bascompte, J., and D. B. Stouffer. 2009. The assembly and disassembly of ecological networks.

447 Philos. Trans. R. Soc. B Biol. Sci. 364:1781-1787.

448

449 Bordes, F., S. Morand, S. Pilosof, J. Claude, B. R. Krasnov, J. F. Cosson, Y. Chaval, A. Ribas, K. 450 Chaisiri, K. Blasdell, V. Herbreteau, S. Dupuy, and A. Tran. 2015. Habitat fragmentation alters 451 the properties of a host-parasite network: Rodents and their helminths in South-East Asia. J. 452 Anim. Ecol. 84:1253-1263.

453

454 Brose, U., A. Ostling, K. Harrison, and N. D. Martinez. 2004. Unified spatial scaling of species 
455 and their trophic interactions. Nature 428:167-171.

456

457 Bui, A. L., T. B. Horwich, and G. C. Fonarow. 2011. Epidemiology and risk profile of heart 458 failure. Nat. Rev. Cardiol. 8:30-41.

459

460 Caballero, Z. C., A. G. Costa-Martins, R. C. Ferreira, J. M. P. Alves, M. G. Serrano, E. P.

461 Camargo, G. A. Buck, P. Minoprio, and M. M. G. Teixeira. 2015. Phylogenetic and syntenic data

462 support a single horizontal transference to a Trypanosoma ancestor of a prokaryotic proline

463 racemase implicated in parasite evasion from host defences. Parasit. Vectors 8:222.

464

465 Cazelles, K., M. B. Araújo, N. Mouquet, and D. Gravel. 2016. A theory for species co-

466 occurrence in interaction networks. Theor. Ecol. 9: 39-48

467

468 Chagas, C. 1909. Nova tripanozomiaze humana: estudos sobre a morfolojia e o ciclo evolutivo 469 do Schizotrypanum cruzi n. gen., n. sp., ajente etiolojico de nova entidade morbida do homem. 470 Mem. Inst. Oswaldo Cruz 1:159-218.

471

472 Cohen, J. M., M. L. Wilson, A. Cruz-Celis, and J. M. Ramsey. 2006. Infestation by Triatoma 473 pallidipennis (Hemiptera: Reduviidae: Triatominae ) is Associated with Housing Characteristics 474 in Rural Mexico Infestation by Triatoma pallidipennis (Hemiptera: Reduviidae: Triatominae). J.

475 Med. Entomology. 43: 1252-1260

476

477 Craft, M. E., and D. Caillaud. 2011. Network models: An underutilized tool in wildlife 
478 epidemiology? Interdiscip. Perspect. Infect. Dis. 676949

479

480 Delgado, S., R. Castillo Neyra, V. R. Quispe Machaca, J. Ancca Juárez, L. Chou Chu, M. R.

481 Verastegui, G. M. Moscoso Apaza, C. D. Bocángel, A. W. Tustin, C. R. Sterling, A. C. Comrie,

482 C. Náquira, J. G. Cornejo del Carpio, R. H. Gilman, C. Bern, and M. Z. Levy. 2011. A history of

483 chagas disease transmission, control, and re-emergence in peri-rural La Joya, Peru. PLoS Negl.

484 Trop. Dis. 5:e970.

485

486 DeStefano, S., and R. M. DeGraaf. 2003. Exploring the Ecology of Suburban Wildlife. Front.

487 Ecol. Environ. 1:95-101.

488

489

DiMichele, W. A., A. K. Behrensmeyer, T. D. Olszewski, C. C. Labandeira, J. M. Pandolfi, S. L.

490

Wing, and R. Bobe. 2004. Long-term stasis in ecological assemblages: evidence from the fossil

491

record. Annu. Rev. Ecol. Evol. Syst. 35:285-322.

492

493

Dirzo, R., H. S. Young, M. Galetti, G. Ceballos, N. J. B. Isaac, and B. Collen. 2014. Defaunation 494 in the Anthropocene. Science. 345:401-406.

495

496

Dumonteil, E., and S. Gourbiére. 2004. Predicting triatoma dimidiata abundance and infection

497 rate: a risk map for natural transmission of chagas disease in the yucatan peninsula of Mexico. Am. J. Trop. Med. Hyg. 70:514-9.

499

500 Enger, K. S., R. Ordoñez, M. L. Wilson, M. Janine, and J. M. Ramsey. 2004. Evaluation of Risk 
501 Factors for Rural Infestation by Triatoma pallidipennis (Hemiptera : Triatominae ), a Mexican

502 Vector of Chagas Disease J. Med. Entomology. 41: 760-767

503

504 Estrada-Peña, A., J. de la Fuente, R. S. Ostfeld, and A. Cabezas-Cruz. 2015. Interactions

505 between tick and transmitted pathogens evolved to minimise competition through nested and 506 coherent networks. Sci. Rep. 5:10361

507

508 Fortuna, M. A., and J. Bascompte. 2008. The Network approach in Ecology. In Unity in

509 Diversity: reflections on ecology after the legacy of Ramón Margalef (Valladares F., Camacho

510 A., Elosegi A., Gracia C., Estrada M., Senar J. C., Gili J. M. [Eds]) pp: 371-392. Fundacion

511 BBVA.

512

513 Francis, R. A., and M. A. Chadwick. 2012. What makes a species synurbic? Appl. Geogr.

$514 \quad 32: 514-521$.

515

516 Freire-de-Lima, L., I. A. Oliveira, J. L. Neves, L. L. Penha, F. Alisson-Silva, W. B. Dias, and A.

517 R. Todeschini. 2012. Sialic acid: A sweet swing between mammalian host and Trypanosoma

518 cruzi. Front. Immunol. 3:1-12.

519

520 Gaunt, M., and M. Miles. 2000. The ecotopes and evolution of triatomine bugs (triatominae) and

521 their associated trypanosomes. Mem. Inst. Oswaldo Cruz 95:557-65.

522

523 Girvan, M., and M. E. J. Newman. 2002. Community structure in social and biological networks. 
524 Proc. Natl. Acad. Sci. 99:7821-6.

525

526 González-Salazar, C., and C. R. Stephens. 2012. Constructing ecological networks: a tool to infer

527 risk of transmission and dispersal of leishmaniasis. Zoonoses Public Health 59 Suppl 2:179-93.

528

529 Gómez, J. M., C. L. Nunn, and M. Verdú. 2013. Centrality in primate-parasite networks reveals

530 the potential for the transmission of emerging infectious diseases to humans. Proc. Natl. Acad.

531 Sci. 110:7738-41.

532

533 Gotelli, N. J. 2000. Null model analysis of species co-occurrence patterns. Ecology 81:26065342621.

535

536 Green, D., and S. Sadedin. 2005. Interactions matter-complexity in landscapes and ecosystems.

537 Ecol. Complex. 2:117-130.

538

539 Guzmán-Tapia, Y., M. Ramirez-Sierra, and E. Dumonteil. 2007. Urban Infestation by Triatoma

540 dimidiata in the city of Merida, Yucatan, Mexico. Vector-Borne Zoonotic Dis. 7:597-606.

541

542 Hamilton, P. B., M. M. G. Teixeira, and J. R. Stevens. 2012. The evolution of Trypanosoma

543 cruzi: the "bat seeding" hypothesis. Trends Parasitol. 28:136-141.

544

545 Heesterbeek, H., R. M. Anderson, V. Andreasen, S. Bansal, D. De Angelis, C. Dye, K. T. D.

546 Eames, W. J. Edmunds, S. D. W. Frost, S. Funk, T. D. Hollingsworth, T. House, V. Isham, P. 
547 Klepac, J. Lessler, J. O. Lloyd-Smith, C. J. E. Metcalf, D. Mollison, L. Pellis, J. R. C. Pulliam, M.

548 G. Roberts, and C. Viboud. 2015. Modeling infectious disease dynamics in the complex

549 landscape of global health. Science 347: aaa4339

550

551 Hotez, P. J., M. E. Bottazzi, C. Franco-Paredes, S. K. Ault, and M. R. Periago. 2008. The

552 neglected tropical diseases of Latin America and the Caribbean: a review of disease burden and

553 distribution and a roadmap for control and elimination. PLoS Negl. Trop. Dis. 2:e300.

554

555 Ibarra-Cerdeña, C. N., V. Sánchez-Cordero, A. T. Peterson, and J. M. Ramsey. 2009. Ecology of

556 North American Triatominae. Acta Trop. 110:178-186.

557

558

Izeta-Alberdi, A., C. N. Ibarra-Cerdeña, D. A. Moo-Llanes, and J. M. Ramsey. 2016.

559 Geographical, landscape and host associations of Trypanosoma cruzi DTUs and lineages. Parasit.

560 Vectors 9:631.

561

562 Jackson, J. B. C., and D. H. Erwin. 2006. What can we learn about ecology and evolution from

563 the fossil record? Trends Ecol. Evol. 21:322-8.

564

565 Jackson, A. P., T. D. Otto, M. Aslett, M. C. Field, M. L. Ginger, M. Berriman, A. P. Jackson, T.

566 D. Otto, M. Aslett, S. D. Armstrong, F. Bringaud, and A. Schlacht. 2016. Kinetoplastid

567 Phylogenomics Reveals the Evolutionary Innovations Associated with the Origins of Parasitism

568 Article Kinetoplastid Phylogenomics Reveals the Evolutionary Innovations Associated with the

569 Origins of Parasitism. Curr. Biol. 26:161-172. 
571 Jansen, A. M., S. C. C. Xavier, and A. L. R. Roque. 2015. The multiple and complex and

572 changeable scenarios of the Trypanosoma cruzi transmission cycle in the sylvatic environment.

573 Acta Trop. 151: 1-15

574

575 Kamada, T., and S. Kawai. 1989. An Algorithm for drawing general undirected grapghs. Inf. 576 Process. Lett. 31:7-15.

577

578 Khlyap, L. A., and A. A. Warshavsky. 2010. Synanthropic and agrophilic rodents as invasive 579 alien mammals. Russ. J. Biol. Invasions 1:301-312.

580

581 Kierszenbaum, F., C. A. Gottlieb, and D. B. Budzko. 1981. Antibody-independent, natural 582 resistance of birds to Trypanosoma cruzi infection. J. Parasitol. 67:656-660.

583

584 Krasnov, B. R., I. S. Khokhlova, G. I. Shenbrot, and R. Poulin. 2008. How are the host spectra of 585 hematophagous parasites shaped over evolutionary time? Random choice vs selection of a 586 phylogenetic lineage. Parasitol. Res. 102:1157-1164.

587

588 Kribs-Zaleta, C. 2010. Estimating contact process saturation in sylvatic transmission of 589 Trypanosoma cruzi in the United States. PLoS Negl. Trop. Dis. 4:e656.

591 Lambrechts, L., T. W. Scott, and D. J. Gubler. 2010. Consequences of the expanding global 592 distribution of Aedes albopictus for dengue virus transmission. PLoS Negl. Trop. Dis. 4:e646. 
594 Legendre, P., D. Borcard, and P. R. Peres-Neto. 2005. Analyzing beta diversity: Partitioning the 595 spatial variation of community composition data. Ecol. Monogr. 75:435-450.

596

597 Lehane, M. J. 2005. The Biology of Blood-Sucking in Insects. Second Ed. Cambridge University 598 Press, New York.

599

600 Lopez-Cancino, S. A., E. Tun-Ku, H. K. De la Cruz-Felix, C. N. Ibarra-Cerdeña, A. Izeta601 Alberdi, A. Pech-May, C. J. Mazariegos-Hidalgo, A. Valdez-Tah, and J. M. Ramsey. 2015.

602 Landscape ecology of Trypanosoma cruzi in the southern Yucatan Peninsula. Acta Trop. 151:

$603 \quad 58-72$

604

605 Losos, J. B., M. Leal, R. E. Glor, K. De Queiroz, P. E. Hertz, L. Rodríguez Schettino, A. C. Lara, 606 T. R. Jackman, and A. Larson. 2003. Niche lability in the evolution of a Caribbean lizard 607 community. Nature 424:542-5.

608

609 Lozano, R., M. Naghavi, K. Foreman, S. Lim, K. Shibuya, V. Aboyans, J. Abraham, T. Adair, R. 610 Aggarwal, S. Y. Ahn, M. Alvarado, H. R. Anderson, L. M. Anderson, K. G. Andrews, C.

611 Atkinson, L. M. Baddour, S. Barker-Collo, D. H. Bartels, M. L. Bell, E. J. Benjamin, D. Bennett, 612 K. Bhalla, B. Bikbov, A. Bin Abdulhak, G. Birbeck, F. Blyth, I. Bolliger, S. Boufous, C. Bucello, 613 M. Burch, P. Burney, J. Carapetis, H. Chen, D. Chou, S. S. Chugh, L. E. Coffeng, S. D. Colan, S. 614 Colquhoun, K. E. Colson, J. Condon, M. D. Connor, L. T. Cooper, M. Corriere, M. Cortinovis, K. 615 C. De Vaccaro, W. Couser, B. C. Cowie, M. H. Criqui, M. Cross, K. C. Dabhadkar, N. 
616 Dahodwala, D. De Leo, L. Degenhardt, A. Delossantos, J. Denenberg, D. C. Des Jarlais, S. D.

617 Dharmaratne, E. R. Dorsey, T. Driscoll, H. Duber, B. Ebel, P. J. Erwin, P. Espindola, M. Ezzati,

618 V. Feigin, A. D. Flaxman, M. H. Forouzanfar, F. G. R. Fowkes, R. Franklin, M. Fransen, M. K.

619 Freeman, S. E. Gabriel, E. Gakidou, F. Gaspari, R. F. Gillum, D. Gonzalez-Medina, Y. A. Halasa,

620 D. Haring, J. E. Harrison, R. Havmoeller, R. J. Hay, B. Hoen, P. J. Hotez, D. Hoy, K. H.

621 Jacobsen, S. L. James, R. Jasrasaria, S. Jayaraman, N. Johns, G. Karthikeyan, N. Kassebaum, A.

622 Keren, J. P. Khoo, L. M. Knowlton, O. Kobusingye, A. Koranteng, R. Krishnamurthi, M.

623 Lipnick, S. E. Lipshultz, S. L. Ohno, J. Mabweijano, M. F. MacIntyre, L. Mallinger, L. March, G.

624 B. Marks, R. Marks, A. Matsumori, R. Matzopoulos, B. M. Mayosi, J. H. McAnulty, M. M.

625 McDermott, J. McGrath, G. A. Mensah, T. R. Merriman, C. Michaud, M. Miller, T. R. Miller, C.

626 Mock, A. O. Mocumbi, A. A. Mokdad, A. Moran, K. Mulholland, M. N. Nair, L. Naldi, K. M. V.

627 Narayan, K. Nasseri, P. Norman, M. O’Donnell, S. B. Omer, K. Ortblad, R. Osborne, D. Ozgediz,

628 B. Pahari, J. D. Pandian, A. P. Rivero, R. P. Padilla, F. Perez-Ruiz, N. Perico, D. Phillips, K.

629 Pierce, C. A. Pope, E. Porrini, F. Pourmalek, M. Raju, D. Ranganathan, J. T. Rehm, D. B. Rein,

630 G. Remuzzi, F. P. Rivara, T. Roberts, F. R. De León, L. C. Rosenfeld, L. Rushton, R. L. Sacco, J.

631 A. Salomon, U. Sampson, E. Sanman, D. C. Schwebel, M. Segui-Gomez, D. S. Shepard, D.

632 Singh, J. Singleton, K. Sliwa, E. Smith, A. Steer, J. A. Taylor, B. Thomas, I. M. Tleyjeh, J. A.

633 Towbin, T. Truelsen, E. A. Undurraga, N. Venketasubramanian, L. Vijayakumar, T. Vos, G. R.

634 Wagner, M. Wang, W. Wang, K. Watt, M. A. Weinstock, R. Weintraub, J. D. Wilkinson, A. D.

635 Woolf, S. Wulf, P. H. Yeh, P. Yip, A. Zabetian, Z. J. Zheng, A. D. Lopez, and C. J. L. Murray.

636 2012. Global and regional mortality from 235 causes of death for 20 age groups in 1990 and

637 2010: A systematic analysis for the Global Burden of Disease Study 2010. Lancet 380:2095-

$638 \quad 2128$. 
640 Maher, S. P., C. Ellis, K. L. Gage, R. E. Enscore, and A. T. Peterson. 2010. Range-wide

641 determinants of plague distribution in North America. Am. J. Trop. Med. Hyg. 83:736-742.

642

643 Martínez-Ibarra, A. J. A. Grant-Guillén Y, Morales-Corona ZY, Haro-Rodríguez S, Ventura-

644 Rodríguez LV, Nogueda-Torres B, and R. Bustos-Saldaña . 2008. Importance of Species of

645 Triatominae (Heteroptera: Reduviidae) in Risk of Transmission of Trypanosoma cruzi in

646 Western Mexico. J. Med Entomology. 45: 476-482

647

648 Martínez-Meyer, E., A. T. Peterson, and W. W. Hargrove. 2004. Ecological niches as stable

649 distributional constraints on mammal species, with implications for Pleistocene extinctions and

650 climate change projections for biodiversity. Glob. Ecol. Biogeogr. 305-314.

651

652 McCauley, D. J., D. J. Salkeld, H. S. Young, R. Makundi, R. Dirzo, R. P. Eckerlin, E. F. Lambin,

653 L. Gaffikin, M. Barry, and K. M. Helgen. 2015. Effects of Land Use on Plague (Yersinia pestis)

654 Activity in Rodents in Tanzania. Am. J. Trop. Med. Hyg.

655

656 McFarlane, R., A. Sleigh, and T. Mcmichael. 2012. Synanthropy of Wild Mammals as a

657 Determinant of Emerging Infectious Diseases in the Asian - Australasian Region. Ecohealth

$6589: 24-35$.

659

660 McKinney, M. L. 2002. Urbanization, Biodiversity, and Conservation. Bioscience 52:883-890.

661 
662 Morris, P. J., L. C. Ivany, K. M. Schopf, and C. E. Brett. 1995. The challenge of paleoecological 663 stasis: reassessing sources of evolutionary stability. Proc. Natl. Acad. Sci. 92:11269-11273.

664

665 Murray, C. J. L., T. Vos, R. Lozano, M. Naghavi, A. D. Flaxman, C. Michaud, M. Ezzati, K. 666 Shibuya, J. A. Salomon, S. Abdalla, V. Aboyans, J. Abraham, I. Ackerman, R. Aggarwal, S. Y. 667 Ahn, M. K. Ali, M. Alvarado, H. R. Anderson, L. M. Anderson, K. G. Andrews, C. Atkinson, L. 668 M. Baddour, A. N. Bahalim, S. Barker-Collo, L. H. Barrero, D. H. Bartels, M. G. Basáñez, A.

Baxter, M. L. Bell, E. J. Benjamin, D. Bennett, E. Bernabé, K. Bhalla, B. Bhandari, B. Bikbov, A.

Bin Abdulhak, G. Birbeck, J. A. Black, H. Blencowe, J. D. Blore, F. Blyth, I. Bolliger, A.

Bonaventure, S. Boufous, R. Bourne, M. Boussinesq, T. Braithwaite, C. Brayne, L. Bridgett, S. 
685 Guillemin, D. Gunnell, R. Gupta, J. Haagsma, H. Hagan, Y. A. Halasa, W. Hall, D. Haring, J. M. 686 Haro, J. E. Harrison, R. Havmoeller, R. J. Hay, H. Higashi, C. Hill, B. Hoen, H. Hoffman, P. J. 687 Hotez, D. Hoy, J. J. Huang, S. E. Ibeanusi, K. H. Jacobsen, S. L. James, D. Jarvis, R. Jasrasaria, 688 S. Jayaraman, N. Johns, J. B. Jonas, G. Karthikeyan, N. Kassebaum, N. Kawakami, A. Keren, J. 689 P. Khoo, C. H. King, L. M. Knowlton, O. Kobusingye, A. Koranteng, R. Krishnamurthi, F. 690 Laden, R. Lalloo, L. L. Laslett, T. Lathlean, J. L. Leasher, Y. Y. Lee, J. Leigh, D. Levinson, S. S. 691 Lim, E. Limb, J. K. Lin, M. Lipnick, S. E. Lipshultz, W. Liu, M. Loane, S. L. Ohno, R. Lyons, J. 692 Mabweijano, M. F. MacIntyre, R. Malekzadeh, L. Mallinger, S. Manivannan, W. Marcenes, L. 693 March, D. J. Margolis, G. B. Marks, R. Marks, A. Matsumori, R. Matzopoulos, B. M. Mayosi, J. 694 H. McAnulty, M. M. McDermott, N. McGill, J. McGrath, M. E. Medina-Mora, M. Meltzer, G. A. 695 Mensah, T. R. Merriman, A. C. Meyer, V. Miglioli, M. Miller, T. R. Miller, P. B. Mitchell, C. 696 Mock, A. O. Mocumbi, T. E. Moffitt, A. A. Mokdad, L. Monasta, M. Montico, M. Moradi697 Lakeh, A. Moran, L. Morawska, R. Mori, M. E. Murdoch, M. K. Mwaniki, K. Naidoo, M. N. 698 Nair, L. Naldi, K. M. V. Narayan, P. K. Nelson, R. G. Nelson, M. C. Nevitt, C. R. Newton, S. 699 Nolte, P. Norman, R. Norman, M. O’Donnell, S. O’Hanlon, C. Olives, S. B. Omer, K. Ortblad, R. 700 Osborne, D. Ozgediz, A. Page, B. Pahari, J. D. Pandian, A. P. Rivero, S. B. Patten, N. Pearce, R. 701 P. Padilla, F. Perez-Ruiz, N. Perico, K. Pesudovs, D. Phillips, M. R. Phillips, K. Pierce, S. Pion, 702 G. V. Polanczyk, S. Polinder, C. A. Pope, S. Popova, E. Porrini, F. Pourmalek, M. Prince, R. L. 703 Pullan, K. D. Ramaiah, D. Ranganathan, H. Razavi, M. Regan, J. T. Rehm, D. B. Rein, G.

704 Remuzzi, K. Richardson, F. P. Rivara, T. Roberts, C. Robinson, F. R. De León, L. Ronfani, R. 705 Room, L. C. Rosenfeld, L. Rushton, R. L. Sacco, S. Saha, U. Sampson, L. Sanchez-Riera, E. 706 Sanman, D. C. Schwebel, J. G. Scott, M. Segui-Gomez, S. Shahraz, D. S. Shepard, H. Shin, R. 707 Shivakoti, D. Singh, G. M. Singh, J. A. Singh, J. Singleton, D. A. Sleet, K. Sliwa, E. Smith, J. L. 
708 Smith, N. J. C. Stapelberg, A. Steer, T. Steiner, W. A. Stolk, L. J. Stovner, C. Sudfeld, S. Syed,

709 G. Tamburlini, M. Tavakkoli, H. R. Taylor, J. A. Taylor, W. J. Taylor, B. Thomas, W. M.

710 Thomson, G. D. Thurston, I. M. Tleyjeh, M. Tonelli, J. A. Towbin, T. Truelsen, M. K.

711 Tsilimbaris, C. Ubeda, E. A. Undurraga, M. J. Van Der Werf, J. Van Os, M. S. Vavilala, N.

712 Venketasubramanian, M. Wang, W. Wang, K. Watt, D. J. Weatherall, M. A. Weinstock, R.

713 Weintraub, M. G. Weisskopf, M. M. Weissman, R. A. White, H. Whiteford, N. Wiebe, S. T.

714 Wiersma, J. D. Wilkinson, H. C. Williams, S. R. M. Williams, E. Witt, F. Wolfe, A. D. Woolf, S.

715 Wulf, P. H. Yeh, A. K. M. Zaidi, Z. J. Zheng, D. Zonies, and A. D. Lopez. 2012. Disability-

716 adjusted life years (DALYs) for 291 diseases and injuries in 21 regions, 1990-2010: A

717 systematic analysis for the Global Burden of Disease Study 2010. Lancet 380: 2197-2223.

718

719 Newman, M. 2006. Modularity and community structure in networks. Proc. Natl. Acad. Sci.

$720 \quad 103: 8577-82$.

721

722 Noireau, F., P. Diosque, and A. M. Jansen. 2009. Trypanosoma cruzi: adaptation to its vectors 723 and its hosts. Vet. Res. 40:26.

724

725 Peterson, A. T., V. Sánchez-Cordero, C. Ben Beard, and J. M. Ramsey. 2002. Ecologic Niche 726 Modeling and Potential Reservoirs for Chagas Disease, Mexico. Emerg. Infect. Dis. 8:662-667. 727

728 Pilosof, S., S. Morand, B. R. Krasnov, and C. L. Nunn. 2015. Potential parasite transmission in 729 multi-host networks based on parasite sharing. PLoS One 10:1-19. 
731 Rabinovich, J. E., U. D. Kitron, Y. Obed, M. Yoshioka, N. Gottdenker, and L. F. Chaves. 2011.

732 Ecological patterns of blood-feeding by kissing-bugs (Hemiptera: Reduviidae: Triatominae).

733 Mem. Inst. Oswaldo Cruz 106:479-94.

734

735 Ramsey, J. M., A. E. Gutierrez-Cabrera, L. Salgado-Ramirez, A. T. Peterson, V. Sanchez-

736 Cordero, and C. N. Ibarra-Cerdeña. 2012. Ecological Connectivity of Trypanosoma cruzi

737 Reservoirs and Triatoma pallidipennis Hosts in an Anthropogenic Landscape with Endemic

738 Chagas Disease. Plos One. 7:e46013.

739

740 Ramsey, J. M., R. Ordonez, A. Cruz-Celis, A. L. Alvear, V. Chavez, R. Lopez, J. R. Pintor, F.

741 Gama, and S. Carrillo. 2000. Distribution of domestic Triatominae and stratification of Chagas

742 Disease transmission in Oaxaca, Mexico. Med. Vet. Entomol. 14:19-30.

743

744 Ramsey, J. M., A T. Peterson, O. Carmona-Castro, D. A Moo-Llanes, Y. Nakazawa, M. Butrick,

745 E. Tun-Ku, K. De la Cruz-Félix, and C. N. Ibarra-Cerdeña. 2015. Atlas of Mexican Triatominae

746 (Reduviidae: Hemiptera) and vector transmission of Chagas disease. Mem. Inst. Oswaldo Cruz

$747 \quad 110: 339-352$.

748

749 Rassi, A. R., A. Rassi, and J. A. Marin-Neto. 2010. Seminar Chagas disease. Lancet 375:13887501402.

751

752 Rubio, A. V., R. Ávila-Flores, and G. Suzán. 2014. Responses of Small Mammals to Habitat

753 Fragmentation: Epidemiological Considerations for Rodent-Borne Hantaviruses in the Americas. 
754 Ecohealth. 11: 526-533

755

756 Ryckman, R. E. 1986. The vertebrate hosts of the Triatominae of North and Central America and

757 the West Indies (Hemiptera: Reduviidae: Triatominae). Bull. Soc. Vector Ecol. 11:221-241.

758

759 Sánchez-Cordero, V., and E. Martínez-Meyer. 2000. Museum specimen data predict crop

760 damage by tropical rodents. Proc. Natl. Acad. Sci. 97:7074-7.

761

762 Shochat, E., P. S. Warren, S. H. Faeth, N. E. McIntyre, and D. Hope. 2006. From patterns to

763 emerging processes in mechanistic urban ecology. Trends Ecol. Evol. 21:186-191.

764

765 Stephens, C. R., H. J. Gimenez, C. Gonzalez, C. N. Ibarra-Cerdeña, V. Sánchez-Cordero, and C.

766 Gonzalez-Salazar. 2009. Using Biotic Interaction Networks for Prediction in Biodiversity and

767 Emerging Diseases. PLoS One 4:e5725.

768

769 Suzán, G., G. E. García-Peña, I. Castro-Arellano, O. Rico, A. V. Rubio, M. J. Tolsá, B. Roche, P.

770 R. Hosseini, A. Rizzoli, K. A. Murray, C. Zambrana-Torrelio, M. Vittecoq, X. Bailly, A. A.

771 Aguirre, P. Daszak, A.-H. Prieur-Richard, J. N. Mills, and J.-F. Guégan. 2015. Metacommunity

772 and phylogenetic structure determine wildlife and zoonotic infectious disease patterns in time

773 and space. Ecol. Evol. 5:865-873.

774

775 Taylor, L. H., S. M. Latham, and M. E. J. woolhouse. 2001. Risk factors for human disease

776 emergence. Philos. Trans. R. Soc. B Biol. Sci. 356:983-989. 
778 Yeo, M., N. Acosta, M. Llewellyn, H. Sánchez, S. Adamson, G. A. J. Miles, E. Lopez, N.

779 Gonzalez, J. S. Patterson, M. W. Gaunt, A. Rojas De Arias, and M. A. Miles. 2005. Origins of

780 Chagas disease: Didelphis species are natural hosts of Trypanosoma cruzi I and armadillos hosts

781 of Trypanosoma cruzi II, including hybrids. Int. J. Parasitol. 35:225-233.

782

783 Young, H. S., R. Dirzo, K. M. Helgen, D. J. McCauley, S. A. Billeter, M. Y. Kosoy, L. M.

784 Osikowicz, D. J. Salkeld, T. P. Young, and K. Dittmar. 2014. Declines in large wildlife increase

785 landscape-level prevalence of rodent-borne disease in Africa. Proc. Natl. Acad. Sci. 111: 7036-

7867041

787

788 Young, H. S., R. Dirzo, D. J. McCauley, B. Agwanda, L. Cattaneo, K. Dittmar, R. P. Eckerlin, R.

789 C. Fleischer, L. E. Helgen, A. Hintz, J. Montenieri, S. Zhao, and K. M. Helgen. 2015. Drivers of

790 intensity and prevalence of flea parasitism on small mammals in East African savanna

791 ecosystems. J. Parasitol. 101: 327-335

792

793

794

795

796

797

798

799 
800

801

802

803

804

805

806

807

808

809 Table 1. Summary of mammals atributes related with their relationships with vector co-

810 occurrences and with Trypanosoma cruzi reports.

\begin{tabular}{lccccccc}
\hline Mammal order & $\begin{array}{c}\text { Species } \\
\text { Artiodactyla }\end{array}$ & $\begin{array}{c}\text { Synanthropic } \\
\text { species }\end{array}$ & $\mathrm{N}$ & $\begin{array}{c}\text { Reservoir } \\
\text { species }\end{array}$ & $\mathrm{N}$ & Links per species & \multicolumn{3}{c}{ Epsilon } \\
\cline { 2 - 8 } Carnivora & 7 & 0 & 0 & 2.6 & 3.4 & 0.29 & 6.06 \\
Chiroptera & 29 & 11 & 9 & 4.9 & 3.95 & 0.15 & 13.65 \\
Cingulata & 131 & 18 & 16 & 4.77 & 4.59 & 0.1 & 17.79 \\
Didelphimorphia & 1 & 1 & 1 & 8 & 2.86 & 0.25 & 4.31 \\
Lagomorpha & 6 & 4 & 4 & 5.3 & 4.91 & 0.63 & 19.42 \\
Pilosa & 2 & 0 & 0 & 5.5 & 4.84 & 0.4 & 13.48 \\
Primates & 3 & 0 & 0 & 4.5 & 4.02 & 0.84 & 10.25 \\
Rodentia & 170 & 0 & 0 & 4.5 & 6.4 & 1.48 & 10.83 \\
Soricomorpha & 15 & 0 & 34 & 3.82 & 5.78 & 0.13 & 24.84 \\
\hline
\end{tabular}

811

812

813

814

815

816 
827 Figure 1. Relation between vector and mammal host species in their distributional range and 828 their corresponding interaction strengths: (A) Number of mammal species within each vector's 829 range and the proportion of these with which the vectors had significant links $(\varepsilon \geq 1.96)$. Red 830 letters indicate bars that are above $(\mathrm{H})$ or below $(\mathrm{L})$, the $95 \%$ confidence interval $(\mathrm{CI})$ of the 831 average number of mammal richness per vectors' range. Blue letters indicate those bars that are 832 above $(\mathrm{H})$ or below $(\mathrm{L})$ the $95 \% \mathrm{CI}$ of the average proportion of mammal species with which 833 vectors had significant links. (B) Mean and standard error of epsilon values for each vector 834 species in their distribution ranges. Black letters indicate the species' vector that has mean 835 epsilons outside of the 95\% CI (H: higher and L: lower). Lack of statistical differences in the 836 epsilon values are indicated for the same color with a $\mathrm{P}<0.05$. (Red and blue colors are used for 837 lower epsilons, while green and purple are used for higher epsilons). 
838

839

840

841

842

843

844

845

846

847

848

849

850

851

852

853

854

855

856

857

858

859

860

861

862

863

864

865

866

867

868

869

870

871

872

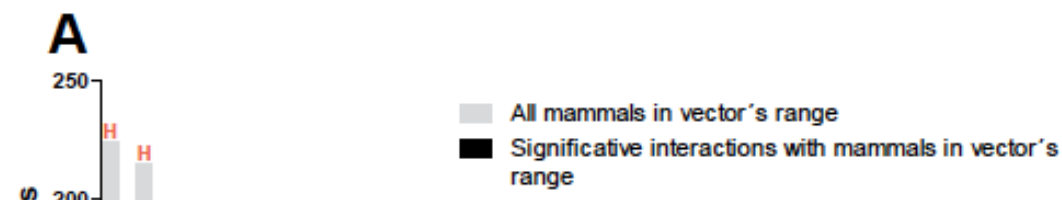

873

874 Figure 2. Evaluation of the performance of the interaction model: T. cruzi potential host species

875

876 are those mammals that were independently reported in the literature as testing positive for natural infections by $T$. cruzi. ${ }^{* * *}$ mean $\mathrm{P}$-values $<0.001$, and ${ }^{* *}$ are $\mathrm{P}$-values $<0.01$. 


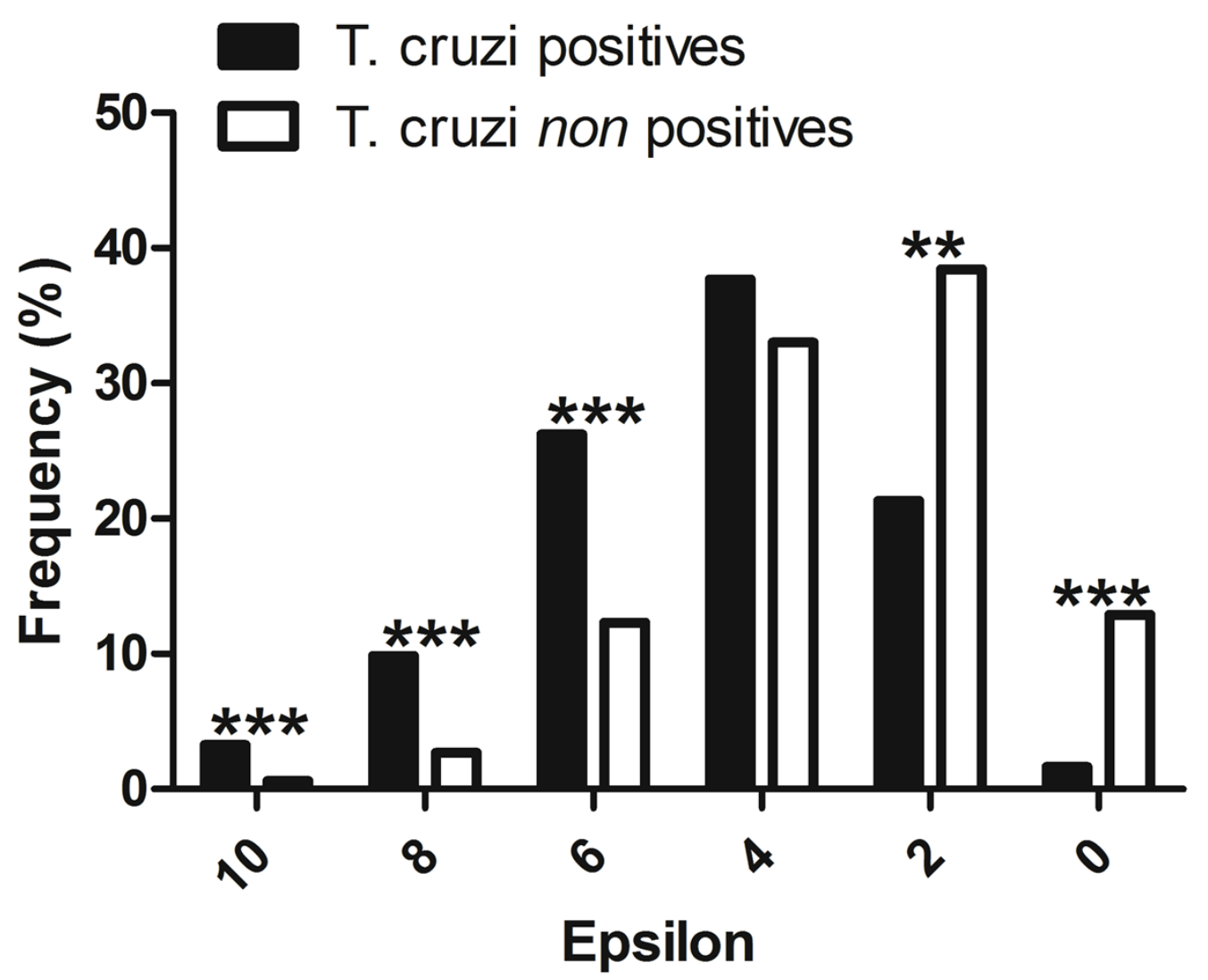

877

878

879

880

881

882

883

884

885

886

887

888

889

890

891

892

893

894

895

896

897

898

899 
900 Figure 3. Network topology projected onto Mexico. The network shows mammal (squares) and 901 vector (circles) nodes linked through edges that represent significant geographic co-occurrence ( $\varepsilon$ $902 \geq 1.96$ ). Each mammal node is located in its range centroid within Mexico. Blue light are 903 synanthropic mammals that are simultaneously infected and probable reservoirs of T. cruzi, 904 yellow squares are synanthropic mammals that have not been reported infected with $T$. cruzi, 905 orange squares are mammals that have been found infected with $T$. cruzi and are not 906 synanthropic, and green squares are mammals that are neithers synanthropic nor have been 907 reported with $T$. cruzi infection. Orange circles are synanthropic triatomines and yellow circles 908 are non-synanthropic triatomines

909

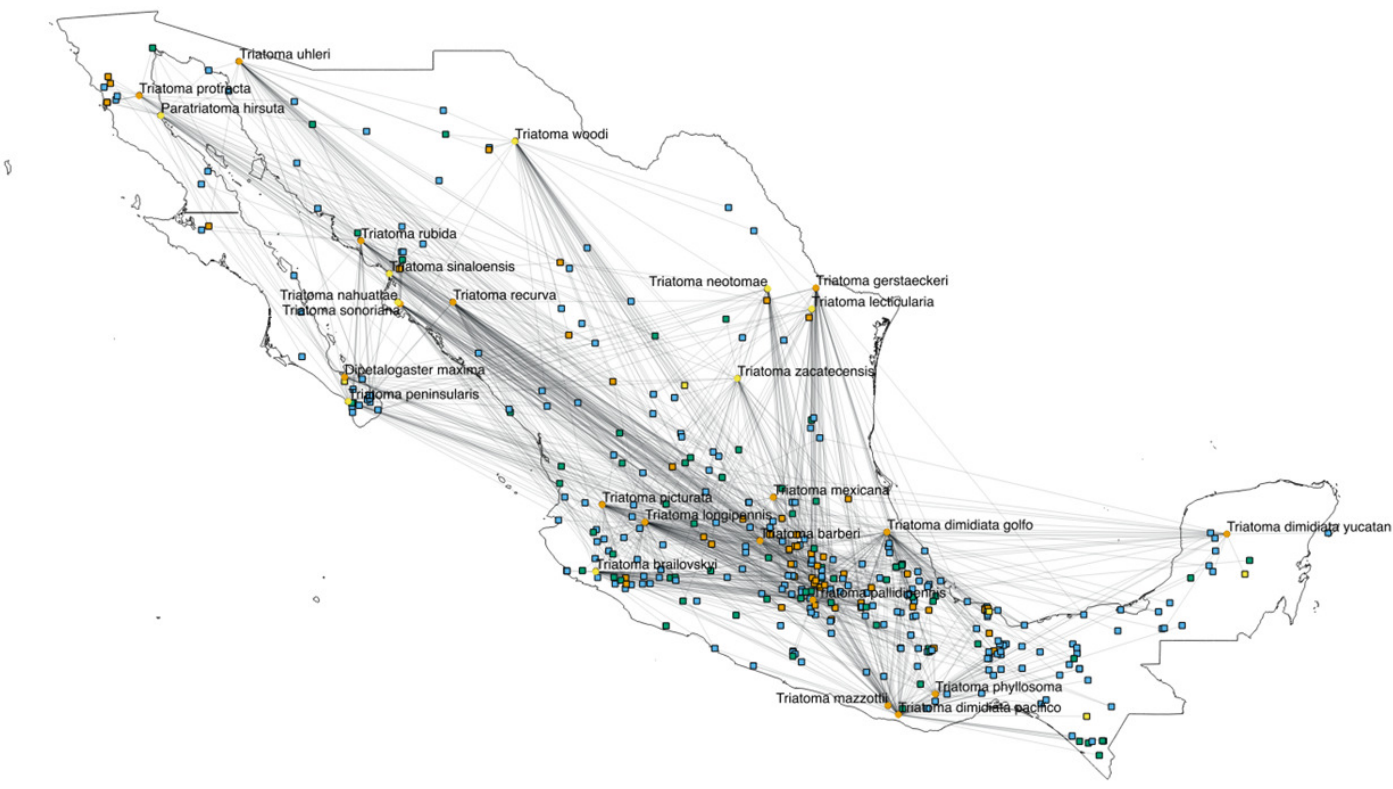


930 Figure 4. Interaction network models for Mexican triatomines and terrestrial mammals. Node 931 position is determined with a Kamada-Kawai algorithm graph. Orange circles are synanthropic 932 triatomines and green circles are non-synanthropic triatomines. Each network depicts resultant

933 links when varying the epsilon threshold; (A) epsilon $\geq 2$, (B) epsilon $\geq 4$, (C) epsilon $\geq 6$, (D) 934 epsilon $\geq 8$, and (E) epsilon $\geq 2$. Blue light are synanthropic mammals that are simultaneously 935 infected and probable reservoirs of T. cruzi, yellow squares are synanthropic mammals that have 936 not been reported infected with $T$. cruzi, orange squares are mammals that have been found

937 infected with $T$. cruzi and are not synanthropic, and green squares are mammals that are neithers 938 synanthropic nor have been reported with T. cruzi infection. 

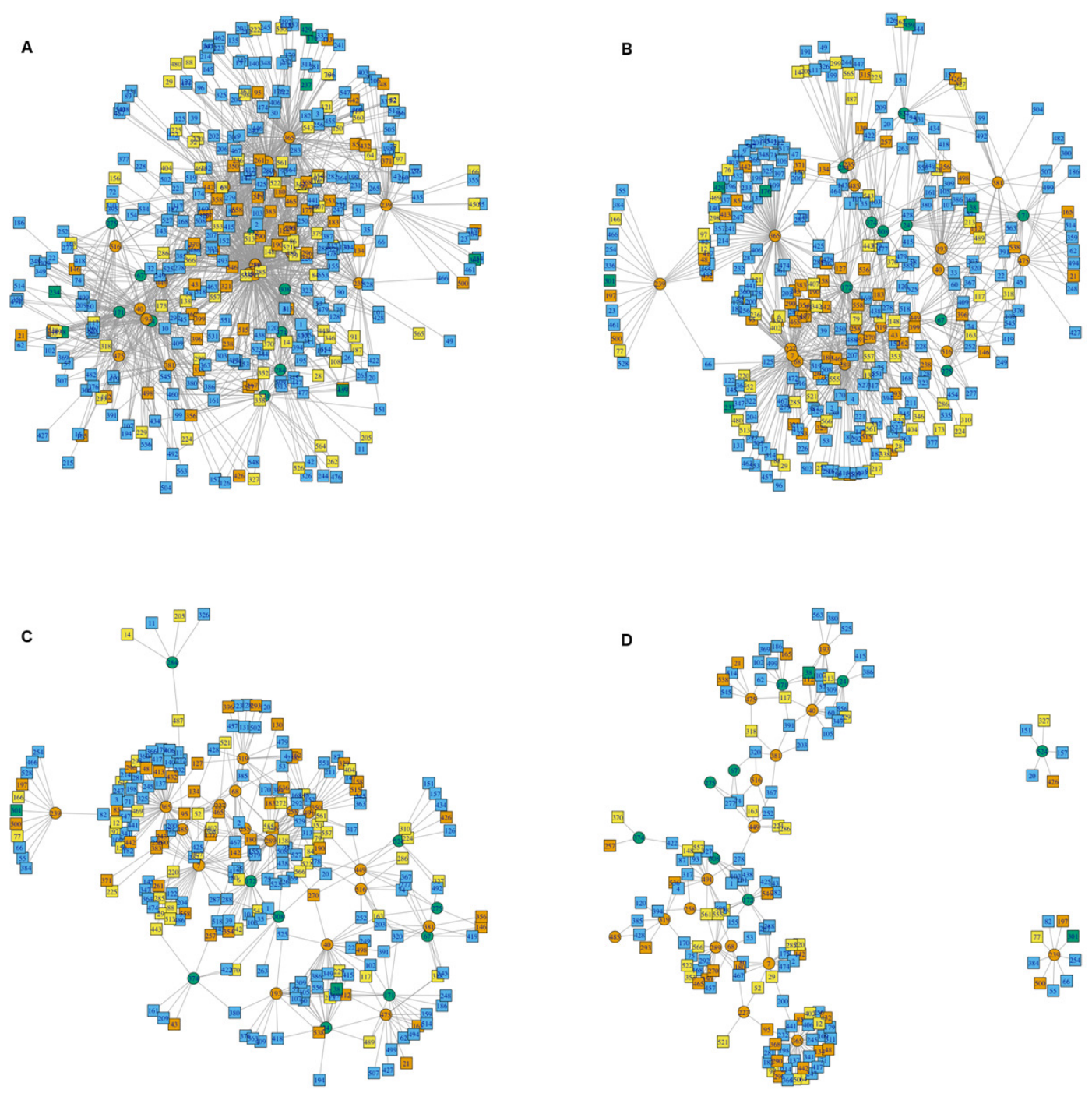

939

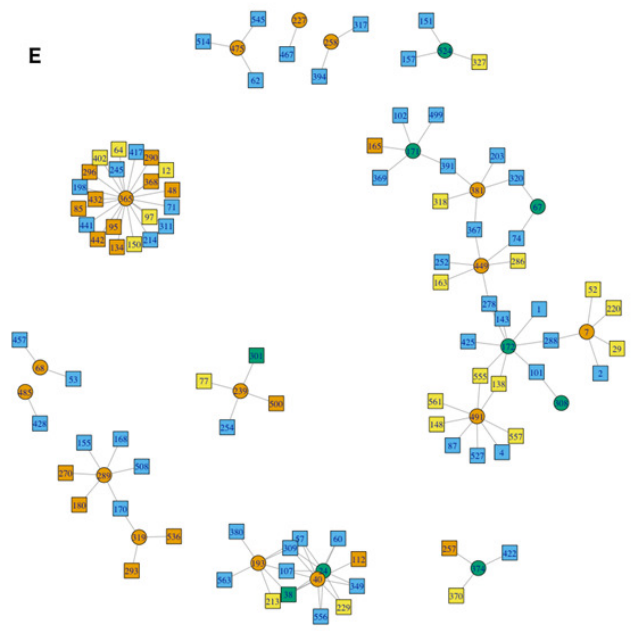

940 
941 Figure 5. Habitat affinities and T. cruzi relationships for vectors (A) and mammal hosts (B) in 942 relation to node importance for the network structure. 

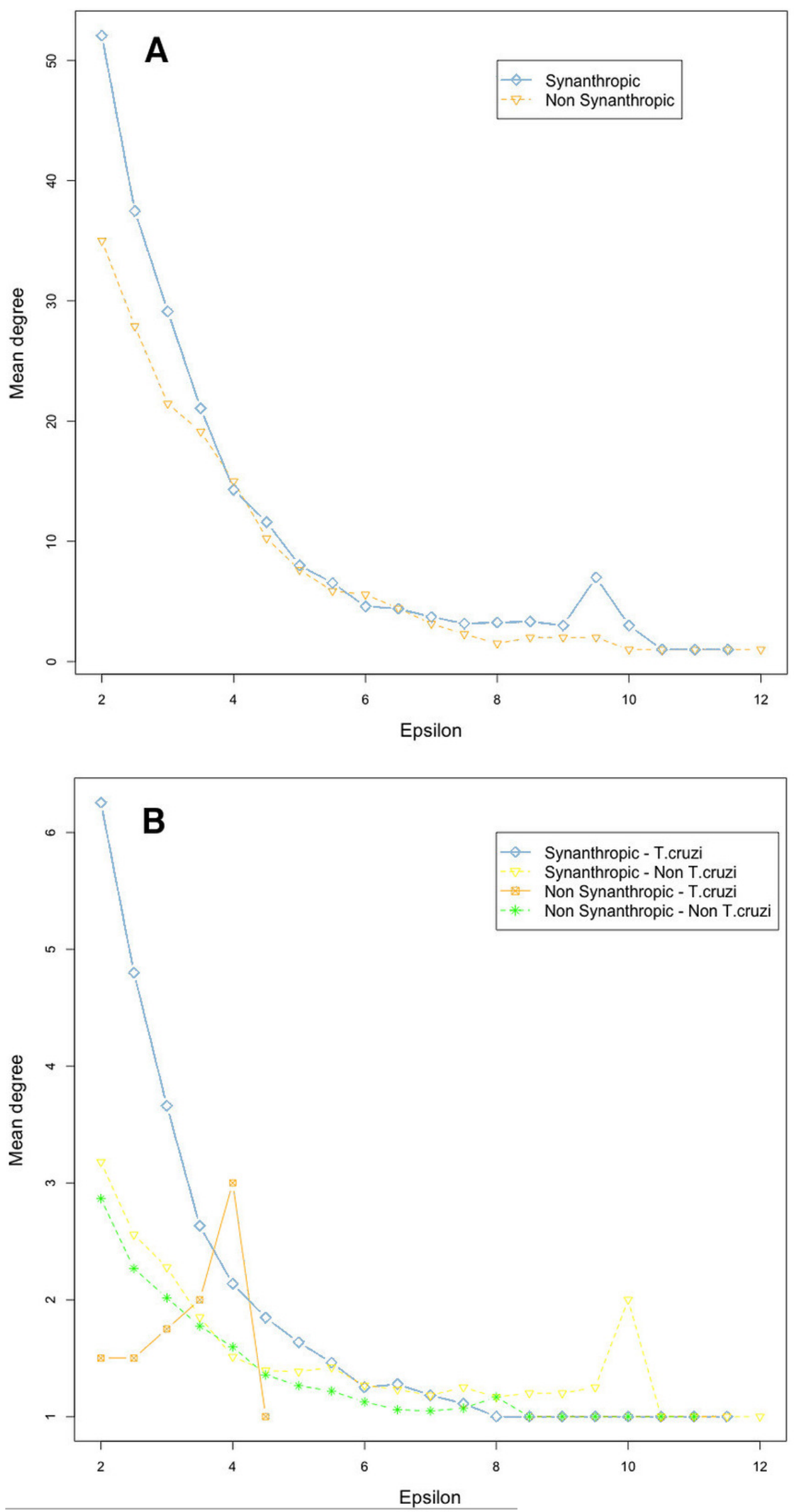
944 Figure 6. Analysis of community structure in the triatomine-mammal host network model. Node 945 size indicates the proportional contribution of each species to its group. Circles represent vectors 946 and squares mammal hosts. Polygones differentiate the two primary clusters, and yellow edges indicate the links that cause community interaction (bridge nodes). Orange circles are

948 synanthropic triatomines and yellow circles are non-synanthropic triatomines. Blue light squares 949 are synanthropic mammals that are simultaneously infected and probable reservoirs of $T$. cruzi, 950 yellow squares are synanthropic mammals that have not been reported infected with $T$. cruzi, 951 orange squares are mammals that have been found infected with $T$. cruzi and are not

952 synanthropic, and green squares are mammals that are neithers synanthropic nor have been reported with $T$. cruzi infection.

954

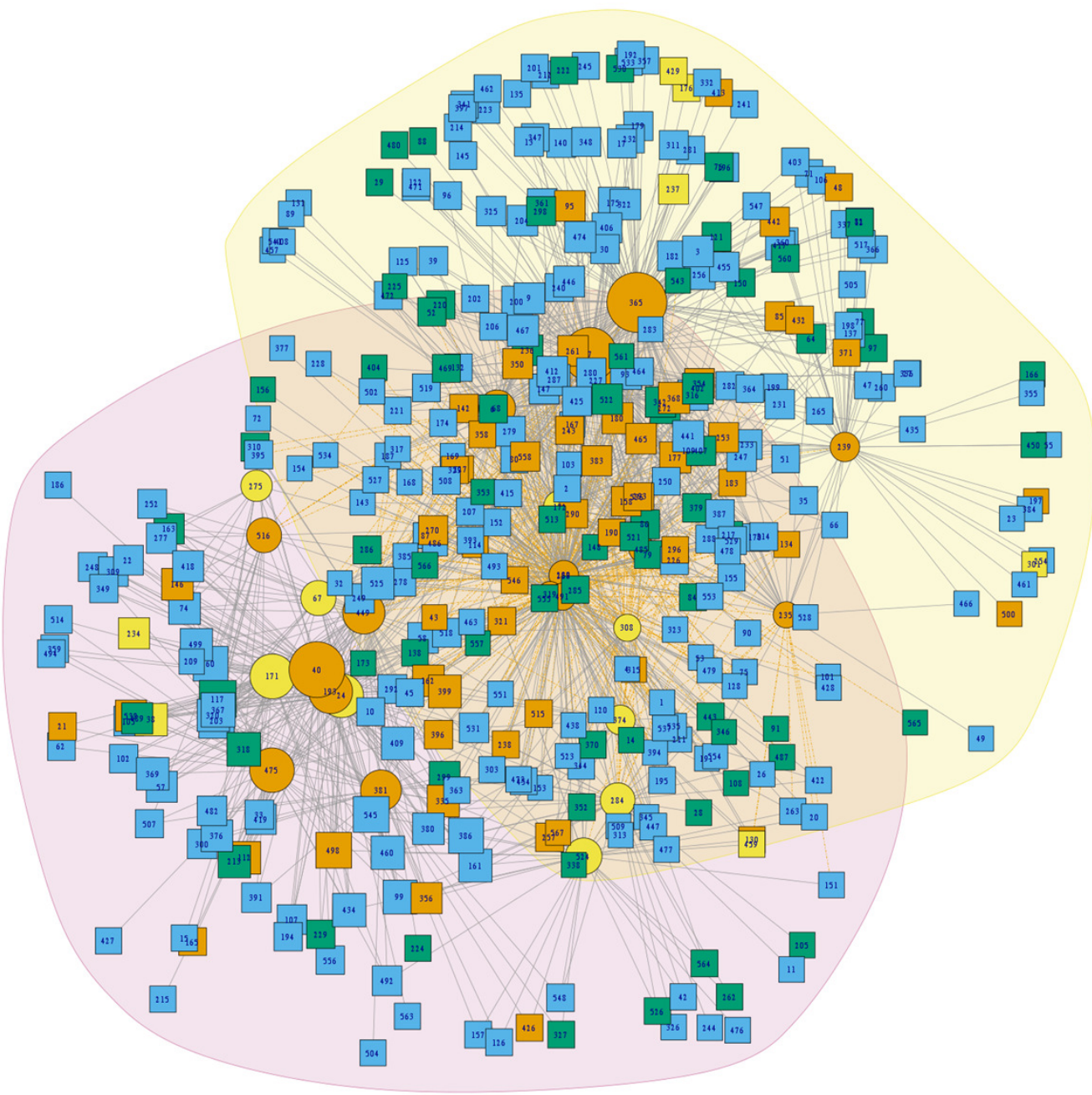


961

962

963

964 Figure 7. Hierarchical clustering of mammal host similarity among vector species.

965

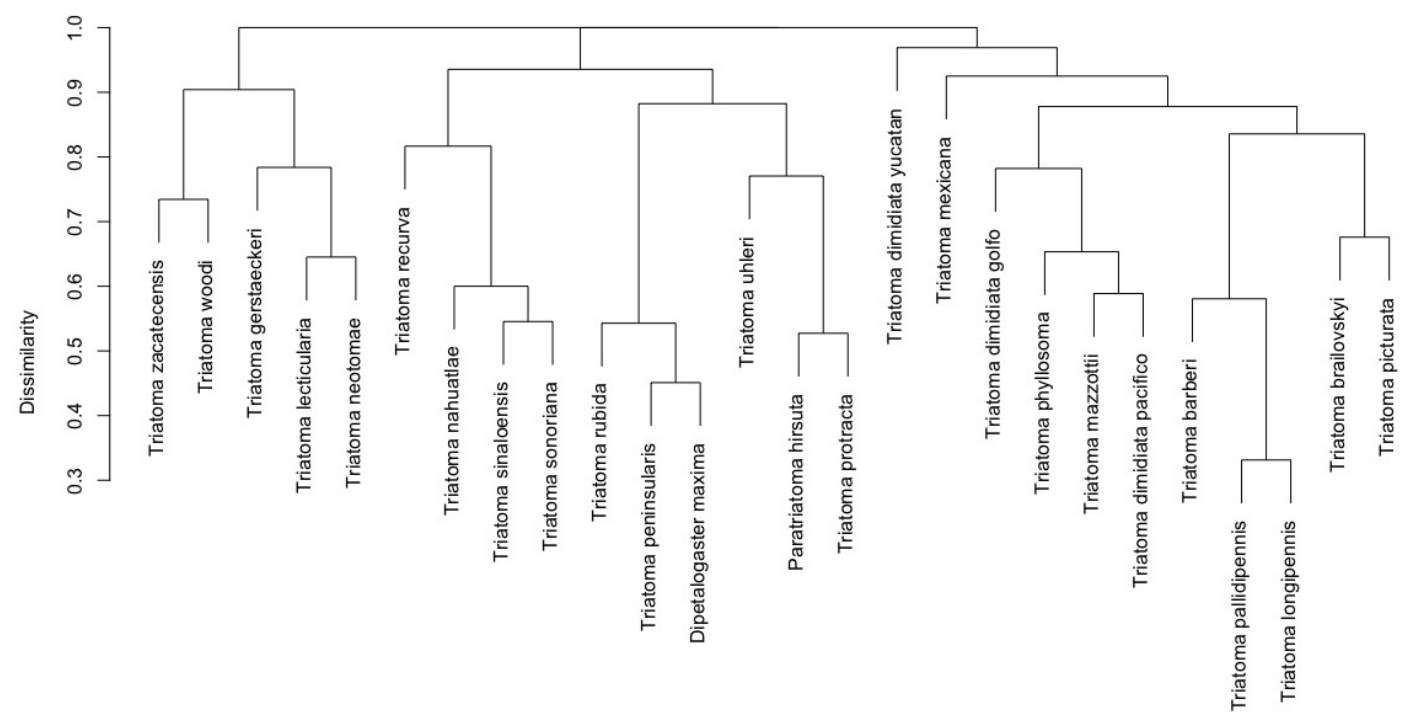

966

967 